\title{
Incidence of Enteric Adenoviruses among Children in Thailand and the Significance of These Viruses in Gastroenteritis
}

\author{
JOHN E. HERRMANN, ${ }^{1 *}$ NEIL R. BLACKLOW,${ }^{1}$ DOROTHY M. PERRON-HENRY, ${ }^{1}$ EMILY CLEMENTS, ${ }^{1}$ \\ DAVID N. TAYLOR, ${ }^{2}$ AND PETER ECHEVERRIA ${ }^{2}$ \\ Division of Infectious Diseases, University of Massachusetts Medical School, Worcester, Massachusetts $01655{ }^{1}$ and \\ Armed Forces Research Institute of Medical Sciences, Bangkok, Thailand ${ }^{2}$
}

Received 5 April 1988/Accepted 31 May 1988

\begin{abstract}
In countries with temperate climates, enteric adenoviruses have been shown to be a substantial cause of pediatric gastroenteritis. To determine the incidence of adenovirus infection in a tropical climate, stools were collected from children under age 7 during a 1-year period at an outpatient clinic in Bangkok, Thailand. Stools from 1,114 children with gastroenteritis and from 947 children without gastroenteritis were tested. Each stool was tested for adenovirus group antigen and for specific enteric adenovirus types (Ad40 and Ad41) by monoclonal antibody enzyme immunoassays. We found that $4.4 \%(49$ of 1,114$)$ of children with gastroenteritis and $1.8 \%$ (17 of 947) of children without gastroenteritis were positive for adenovirus group antigen. In tests for specific enteric adenovirus types, $2.0 \%(22$ of 1,114$)$ of the tests were positive in children with gastroenteritis and $0.6 \%$ (6 of 947) were positive in children without gastroenteritis. There was a significant correlation $(P<$ 0.02) of gastroenteritis with nonenteric adenovirus types $(27$ of 1,114$)$ as well as with specific enteric adenovirus types $(P<0.01)$. By comparison, $19.7 \%$ of children with gastroenteritis and $0.7 \%$ of those without gastroenteritis were positive for rotavirus infection. In the adenovirus-infected children with gastroenteritis, there were coinfections with rotavirus only in those with nonenteric adenovirus infection (7 of 27 children). There were no significant differences in the association of bacterial or parasitic infections with either enteric or nonenteric adenovirus infections in either group of children studied. These data demonstrate that Ad40 and Ad41 are causes of gastroenteritis in this population, but among the spectrum of diarrheal etiologies, they may be proportionately less important than they are in countries with temperate climates.
\end{abstract}

It is now well established that two distinct serotypes of adenovirus, types 40 and 41 , are the major types involved in the etiology of adenoviral gastroenteritis. These enteric adenoviruses have been frequently identified in the stools of infants and young children with diarrhea in countries which have temperate climates $(1,2,7,8,16,17)$, and among viruses studied, they may be second in importance only to rotaviruses (16). The percentage of cases of gastroenteritis due to enteric adenoviruses has been variable in these countries, with an approximate range of 6 to $8 \%$ (13). Studies concerning the incidence of enteric adenovirus have utilized either type-specific identification techniques or, more frequently, presumptive methods. In the latter methods, electron microscopy (EM) is usually used in tandem with growth characteristics of enteric adenoviruses in cell cultures. The most comprehensive study which utilized the type-specific identification methods was done by Uhnoo et al. (17) in Uppsala, Sweden, who reported a 7.9\% (33 of 416) incidence of Ad40 or Ad41 in samples collected during a 1-year period. In studies using presumptive methods, Cevenini et al. (5) found an infection rate of $8.3 \%$ (325 of 3,932) for enteric adenovirus during a 5-year period in Bologna, Italy, and Leite et al. (12) reported a $1.9 \%$ (14 of 746) rate in a 2-year study done in Rio de Janeiro, Brazil. A study in Osaka, Japan, which used only EM, found that $6 \%$ (23 of 395) of diarrheic samples contained adenovirus particles (14). EM detects both enteric and nonenteric adenovirus, but in stools from symptomatic cases, it is likely that 60 to $80 \%$ of the adenovirus detected by EM are enteric types $(2,16)$. Thus, use of EM alone can give a general indication of enteric adenovirus incidence. Extensive studies by Brandt et al. (1)

\footnotetext{
* Corresponding author.
}

using EM alone have shown that over an 8-year period, the detection of adenovirus particles in stools was quite variable from year to year, ranging from 1.4 to $10.7 \%$ of the samples examined.

Both types of enteric adenovirus have been isolated from cases of gastroenteritis in countries with tropical climates, but no epidemiological studies on their incidence have been reported. In this study, we have examined 1,114 stools collected from children with gastroenteritis and 947 stools from children without gastroenteritis who were seen in an outpatient clinic in Bangkok, Thailand, for the presence of enteric and nonenteric adenoviruses. The stools were also examined for the presence of rotavirus to determine the relative frequency of each of the viruses as etiologic agents of gastroenteritis in this population.

\section{MATERIALS AND METHODS}

Stool specimens. Stools were obtained from children under age 7 during a 1-year period at an outpatient clinic in Bangkok, Thailand. Of 2,061 stool samples collected, 1,114 were obtained from children with gastroenteritis, and 947 were obtained from children of similar ages who visited the clinic for reasons other than gastroenteritis. Stools from patients with gastroenteritis were tested for parasites and for bacterial pathogens, including Salmonella spp., Shigella spp., enterotoxigenic Escherichia coli, Campylobacter jejuni, Plesiomonas shigelloides, and Vibrio spp., by methods previously described (15). Stools were frozen and stored at $-70^{\circ} \mathrm{C}$ for later viral testing.

Detection of adenoviruses and rotavirus. Stool samples were tested as $10 \%(\mathrm{wt} / \mathrm{vol})$ suspensions in phosphatebuffered saline (PBS), pH 7.0, for adenovirus group antigen, Ad40, Ad41, and group A rotavirus by monoclonal antibody- 
TABLE 1. Incidence of enteric adenoviruses, nonenteric adenoviruses, and group A rotavirus in stools from children with and without gastroenteritis

\begin{tabular}{lrrrr}
\hline \multirow{2}{*}{ Condition of children } & \multirow{2}{*}{$\begin{array}{c}\text { No. of } \\
\text { children }\end{array}$} & \multicolumn{2}{c}{ No. (\%) of children virus positive } \\
\cline { 3 - 4 } & tested & \multicolumn{2}{c}{ Adenoviruses } & \multirow{2}{*}{ Rotavirus } \\
\cline { 3 - 4 } & & Enteric $^{a}$ & Nonenteric $^{b}$ & \\
\hline With gastroenteritis & 1,114 & $22(2.0)$ & $27(2.4)$ & $220(19.7)$ \\
Without gastroenteritis & 947 & $6(0.61)$ & $11(1.2)$ & $7(0.7)$ \\
\hline
\end{tabular}

${ }^{a} P<0.01$

${ }^{b} P<0.02$

based enzyme-linked immunosorbent assays (ELISAs). The ELISAs for the enteric adenovirus types were performed with a mixture of monoclonal antibodies to each type (11) in a format previously described and validated by us (10). In brief, wells of microdilution plates were coated either with guinea pig anti-adenovirus type 7 , which contained antibody to adenovirus group antigen, or with rabbit anti-rotavirus SA11 for the rotavirus assay (9). Antibodies were diluted in $0.01 \mathrm{M}$ PBS, pH 7.0, to contain approximately $10 \mu \mathrm{g} / \mathrm{ml}$. Stool suspensions $(10 \%$ [wt/vol] in PBS) were added $(0.05$ $\mathrm{ml}$ ) and incubated for $1 \mathrm{~h}$ at $37^{\circ} \mathrm{C}$ for the rotavirus assay or overnight at 20 to $22^{\circ} \mathrm{C}$ for the adenovirus tests. The plates were washed five times with PBS here and after subsequent steps. A mixture of monoclonal antibodies to Ad40 and Ad41 or to rotavirus VP6 antigen (6) was added to the wells and incubated for $1 \mathrm{~h}$ at $37^{\circ} \mathrm{C}$. Peroxidase-labeled goat antimouse immunoglobulin G, heavy and light chains (Kirkegaard and Perry Laboratories, Gaithersburg, Md.), at $1 \mu \mathrm{g}$ / $\mathrm{ml}$ was added and incubated for $1 \mathrm{~h}$ at $37^{\circ} \mathrm{C}$. The diluent used for antibody and conjugate was $0.1 \mathrm{M}$ Tris hydrochloride

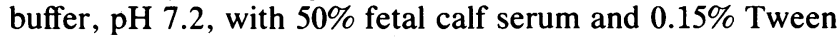
20 added. The plates were washed, soaked for 30 s with PBS containing $0.05 \%$ Tween 20 , and washed again. All plate washing was done with an automatic plate washer (Skatron, Lier, Norway). Substrate for peroxidase was added $(0.1 \mathrm{ml}$ of $o$-phenylenediamine- $\mathrm{H}_{2} \mathrm{O}_{2}$; Abbott Laboratories, North Chicago, Ill.), for $10 \mathrm{~min}$, and the reaction was stopped with $0.2 \mathrm{ml}$ of $1 \mathrm{~N} \mathrm{H}_{2} \mathrm{SO}_{4}$. The $A_{490}$ of the solution was measured in a plate reader spectrophotometer. Samples were considered positive for virus antigen if the absorbance value was $\geq 0.1$ and more than three times that of the negative control (negative stool in PBS).

For detection of adenovirus group antigen, a monoclonal antibody to adenovirus hexon group antigen (4), obtained from the American Type Culture Collection, Rockville, Md., was substituted for the Ad40 and Ad41 mixture of monoclonal antibodies in the ELISA.

\section{RESULTS}

The detection rates for each of the virus groups assayed in children with and without gastroenteritis are given in Table 1. Although rotavirus was clearly the major viral pathogen detected, there was a significantly higher $(P<0.01)$ detection rate of enteric adenovirus in those children with diarrhea than in those without diarrhea. There was also a significant $(P<0.02)$ association of nonenteric adenovirus with gastroenteritis. The Fisher exact test was used for these and subsequent determinations of significance.

The age distribution of children from each group infected with either enteric or nonenteric adenovirus is shown in Fig. 1. In the gastroenteritis group, $86 \%$ (19 of 22) of children

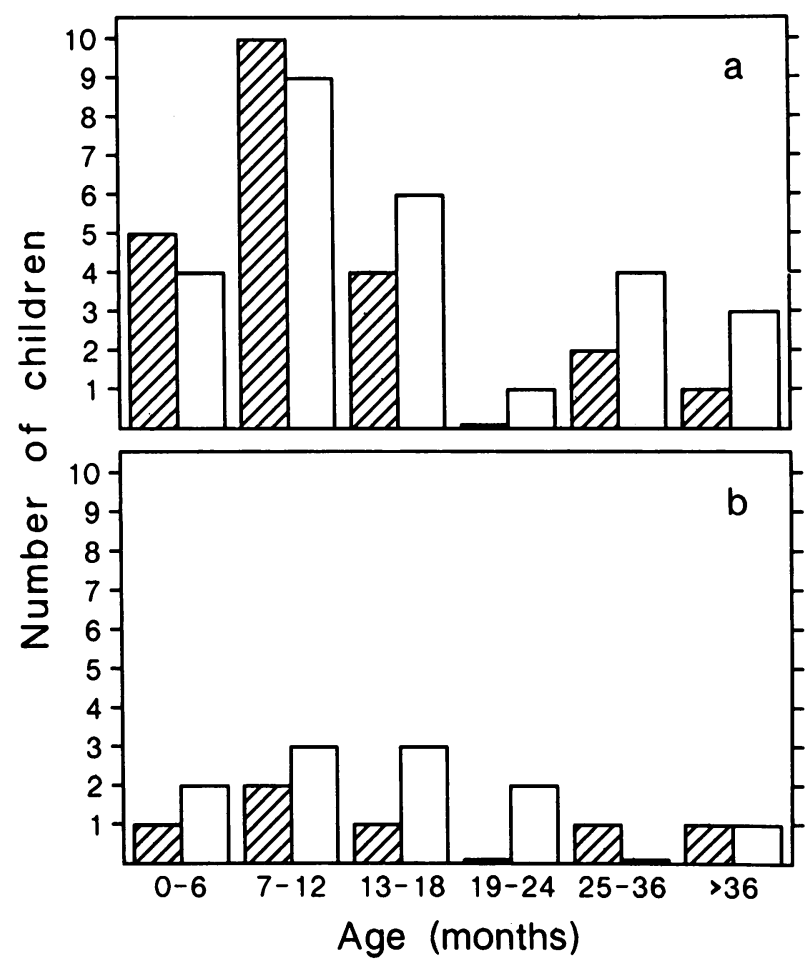

FIG. 1. Age distribution of children infected with enteric (包) or nonenteric ( $\square$ ) adenovirus and with (a) and without (b) gastroenteritis.

with enteric adenovirus and $70 \%$ (19 of 27) of those with nonenteric adenovirus were 18 months of age or younger. Of children without gastroenteritis, $67 \%$ (4 of 6 ) of those with enteric adenovirus and $73 \%$ (8 of 11$)$ of those with nonenteric adenovirus were 18 months of age or younger. There were no apparent seasonal trends with either enteric or nonenteric adenovirus, nor were there significant differences in respiratory symptoms in those with either enteric or nonenteric adenovirus.

Assays for bacterial and parasitic pathogens were performed on samples from the groups with and without gastroenteritis. In the group with gastroenteritis, children with viral infections frequently had coinfections with other pathogens as well (Table 2). The coinfecting agents most frequently involved with rotavirus and all adenovirus types were Salmonella spp. (5 to $14 \%$ ), enteropathogenic $E$. coli ( 7 to $10 \%$ ), and $C$. jejuni (8 to $10 \%$ ). Giardia lamblia was recovered from $8 \%$ of the samples with the enteric adenovirus types but from less than $1 \%$ of those with nonenteric adenovirus or rotavirus. $P$. shigelloides was isolated from $5 \%$ of children with nonenteric adenovirus. There were fewer children without gastroenteritis who had rotavirus or adenovirus infections, but of those infected, Salmonella spp., enteropathogenic $E$. coli, and $C$. jejuni were the major agents isolated. There were no significant differences in the number of coinfections of enteric or nonenteric adenovirus with bacteria or parasites in children with or without gastroenteritis $(P=0.32$ and 0.35 for enteric and nonenteric adenovirus, respectively).

Most of the major pathogens in children without a detectable virus infection were the same as those in each group of infected children, with Salmonella spp. occurring in 10 to $13 \%$ and $C$. jejuni occurring in 9 to $11 \%$. However, Shigella spp. were isolated from $14 \%$ of the children with gastroen- 
TABLE 2. Coinfection of children with viral and bacterial or parasitic pathogens

\begin{tabular}{lllll}
\hline \multirow{2}{*}{ Virus detected $^{a}$} & \multicolumn{2}{c}{ \% of children (no. positive/total no.) } \\
\cline { 2 - 3 } & \multicolumn{2}{c}{ Infected $^{b}$} & & \multicolumn{2}{c}{ Uninfected } \\
\cline { 2 - 5 } & With diarrhea & Without diarrhea & & With diarrhea \\
\hline Enteric adenovirus & $54.6(12 / 22)^{c, d}$ & $33.3(2 / 6)^{d}$ & $45.4(10 / 22)$ & Without diarrhea \\
Nonenteric adenovirus & $40.7(11 / 27)^{c . e}$ & $36.4(4 / 11)^{e}$ & $59.3(16 / 27)$ & $63.7(4 / 6)$ \\
Rotavirus & $35.5(78 / 220)$ & $14.3(1 / 7)$ & $64.5(142 / 220)$ & $85.7(6 / 7)$ \\
None & $48.3(411 / 851)$ & $31.5(291 / 923)$ & $51.7(440 / 851)$ & $68.5(623 / 923)$ \\
\hline
\end{tabular}

$a$ The total number of diarrheic children tested was 1,114. However, because there were six coinfections of rotavirus and nonenteric adenovirus, the sum of the denominators for children tested in this group is 1,120 .

${ }^{b}$ With bacteria or parasites.

c $P=0.25$.

${ }^{d} P=0.32$.

e $P=0.35$.

teritis, compared with $<1 \%$ of those without enteric illness. Because of this, there were significantly more $(P<0.0001)$ infections in the illness group. In the gastroenteritis group with viral infections, there were no Shigella spp. infections in children with enteric adenovirus infection, $6 \%$ in children with nonenteric adenovirus, and $3 \%$ in children with rotavirus infection. Rotavirus coinfections occurred in 7 of 27 children in the diarrheic, nonenteric adenovirus group compared with 0 of 22 in the enteric adenovirus group $(P=0.02)$.

\section{DISCUSSION}

The results of the investigation of a large number of stool samples demonstrate that enteric adenovirus types are significantly associated $(P<0.01)$ with pediatric gastroenteritis in the Thai population studied. There was also a significant association $(P<0.02)$ of nonenteric adenovirus infection with gastroenteritis ( 27 patients). Of these 27,7 were coinfected with rotavirus, which may have been a factor in their illness. The specific adenovirus serotypes involved were not analyzed, but we assume that they do not represent enteric types missed by the ELISA used for their detection. We have shown previously that our ELISA for enteric adenovirus detected 57 of 59 samples positive by EM and cell culture. Also, the ELISA values for the group antigen test were generally the same as or lower than those obtained for samples positive by the enteric type-specific ELISA, and the ELISA group antigen gave lower endpoints by serial dilution of cell-cultivated Ad40 and Ad41 (data not shown). Furthermore, it has been demonstrated that the quantity of enteric adenovirus particles in stools as determined by EM is usually far higher than that of the nonenteric adenovirus types, a finding which can be used for presumptive diagnosis of enteric adenovirus types by EM (3). Thus, it is unlikely that samples were missed by the specific enteric adenovirus test and detected by the group antigen test.

Infection with nonviral pathogens was common among children with gastroenteritis, but excluding the rates for Shigella spp. infection, infection rates were not significantly different $(P>0.05)$ from those among children without gastroenteritis. The incidence of coinfection was no higher $(P=0.25)$ among those with gastroenteritis and enteric adenovirus infection than among those with other adenoviruses (Table 2). Thus, the gastroenteritis seen in children with adenovirus infection can be considered, in most cases, a result of viral infection alone.

The pattern of infection with enteric and nonenteric adenoviruses, association of these viruses with gastroenteritis, and coinfection of patients with other pathogens is similar to the pattern found in a study of 416 ill children in a temperate climate in Uppsala, Sweden (17). The percentage of total adenovirus specimens identified as enteric was somewhat higher in that study (59\% [33 of 56] compared with the $45 \%$ [22 of 49] that we found in Thailand), and the overall incidence of enteric adenovirus as well as the total adenovirus was higher in that population than in the one we studied (7.9 and $13.5 \%$ versus 2.0 and $4.4 \%$, respectively).

We conclude that the enteric adenovirus types are a cause of gastroenteritis in the Thai children studied. However, as a proportion of total diarrheal diseases, the incidence of enteric adenovirus in this group was less than that found in most reports to date from areas with temperate climates.

\section{ACKNOWLEDGMENT}

This work was supported by contract DAMD 17-86-C6196 from the U.S. Army Medical Research and Development Command.

\section{LITERATURE CITED}

1. Brandt, C. D., H. W. Kim, W. J. Rodriguez, J. O. Arrobio, B. C. Jeffries, E. P. Stallings, C. Lewis, A. J. Miles, R. M. Chanock, A. Z. Kapikian, and R. H. Parrott. 1983. Pediatric viral gastroenteritis during eight years of study. J. Clin. Microbiol. 18: 71-78.

2. Brandt, C. D., H. W. Kim, W. J. Rodriguez, J. O. Arrobio, B. C. Jeffries, E. P. Stallings, C. Lewis, A. J. Miles, M. K. Gardner, and R. H. Parrott. 1985. Adenoviruses and pediatric gastroenteritis. J. Infect. Dis. 151:437-443.

3. Brandt, C. D., W. J. Rodriguez, H. W. Kim, J. O. Arrobio, B. C. Jeffries, and R. H. Parrott. 1984. Rapid presumptive recognition of diarrhea-associated adenoviruses. J. Clin. Microbiol. 20: 1008-1009.

4. Cepko, C. L., C. A. Whetstone, and P. A. Sharp. 1983. Adenovirus hexon monoclonal antibody that is group specific and potentially useful as a diagnostic reagent. J. Clin. Microbiol. 17: 360-364.

5. Cevenini, R., R. Mazzaracchio, F. Rumpianesi, M. Donati, A. Moroni, V. Sambri, and M. La Placa. 1987. Prevalence of enteric adenovirus from acute gastroenteritis: a five year study. Eur. J. Epidemiol. 3:147-150.

6. Cukor, G., D. M. Perron, R. Hudson, and N. R. Blacklow. 1984. Detection of rotavirus in human stools by using monoclonal antibody. J. Clin. Microbiol. 19:888-892.

7. DeJong, J. C., R. Wigand, A. H. Kidd, G. Wadell, J. G. Kapsenberg, C. J. Muzerie, A. G. Wermenbol, and R. G. Firtzlaff. 1983. Candidate adenoviruses 40 and 41 : fastidious adenoviruses from human infant stool. J. Med. Virol. 11:215231.

8. Gary, G. W., Jr., J. C. Hierholzer, and R. E. Black. 1979. Characteristics of noncultivable adenoviruses associated with diarrhea in infants: a new subgroup of human adenoviruses. $J$. Clin. Microbiol. 10:96-103. 
9. Herrmann, J. E., N. R. Blacklow, D. M. Perron, G. Cukor, P. J. Krause, J. S. Hyams, H. J. Barrett, and P. L. Ogra. 1985. Enzyme immunoassay with monoclonal antibodies for the detection of rotavirus in stool specimens. J. Infect. Dis. 152:830 832.

10. Herrmann, J. E., D. M. Perron-Henry, and N. R. Blacklow. 1987. Antigen detection with monoclonal antibodies for the diagnosis of adenovirus gastroenteritis. J. Infect. Dis. 155:11671171.

11. Herrmann, J. E., D. M. Perron-Henry, D. Stobbs-Walro, and N. R. Blacklow. 1987. Preparation and characterization of monoclonal antibodies to enteric adenovirus types 40 and 41 . Arch. Virol. 94:259-265.

12. Leite, J. P. G., H. G. Pereira, R. S. Azeredo, and H. G. Schatzmayr. 1985. Adenoviruses in faeces of children with acute gastroenteritis in Rio de Janeiro, Brazil. J. Med. Virol. 15:203209.

13. Madeley, C. R. 1986. The emerging role of adenoviruses as inducers of gastroenteritis. Pediatr. Infect. Dis. J. 5:S63-S74.

14. Oishi, I., K. Yamazaki, Y. Minekawa, H. Nishimura, and T. Kitaura. 1985. Three year survey of the epidemiology of rotavirus, enteric adenovirus, and some small spherical viruses associated with infantile diarrhea. Biken J. 28:9-19.

15. Taylor, D. N., P. Echeverria, T. Pal, O. Sethabutr, S. Saiborisuth, S. Sricharmorn, B. Rowe, and J. Cross. 1986. The role of Shigella spp., enteroinvasive Escherichia coli, and other pathogens as causes of childhood dysentery in Thailand. J. Infect. Dis. 153:1132-1138.

16. Uhnoo, I., G. Wadell, L. Svensson, and M. E. Johansson. 1983. Two new serotypes of enteric adenovirus causing infantile diarrhoea. Dev. Biol. Stand. 53:311-318.

17. Uhnoo, I., G. Wadell, L. Svensson, and M. E. Johansson. 1984. Importance of enteric adenoviruses 40 and 41 in acute gastroenteritis in infants and young children. J. Clin. Microbiol. 20:365372. 